\title{
EVOLUTIONARY CONSERVATION OF DNA CODING FOR MATERNAL RNA IN SEA URCHINS
}

Gordon P. Moore

Division of Biological Sciences, The University of Michigan, Ann Arbor, Michigan 48109-1048

Received Apri1 20, 1984

The extent of evolutionary conservation of DNA complimentary to RNA stored in the mature oocyte of the sea urchin $S$. purpuratus has been assessed. To do this, such DNA was hybridized with total genomic DNA of $S$. purpuratus and $s$. franciscanus and the thermal stability of the resultant duplexes was measured by two methods. In the first method, the duplexes were bound to hydroxylapatite and thermally eluted; the difference in thermal stability between homologous and heterologous duplexes averaged $6.9^{\circ} \mathrm{C}$ in duplicate determinations. In the second experiment, the same hybrids were thermally melted in $2.4 M$ tetraethylammonium chloride, then assayed with S1 nuclease; the difference in thermal stability of homologous and heterologous duplexes was $4.8^{\circ} \mathrm{C}$. Either value is significantly lower than the divergence of total single-copy DNA among these species as measured by the same techniques. This demonstrates that DNA sequences complimentary to maternal RNA are conserved during evolution, and thus that a high fraction of them are likely to be physiologically functional.

An important interface in modern molecular biology is that between the study of evolution and of development. To further our understanding of the evolution of developmental processes at the molecular level, it is important to examine the evolutionary history of developmentally significant molecules. A particularly interesting population of such molecules is the RNA stored in the mature sea urchin oocyte. These sequences, termed "maternal RNA", have been extensively studied, but neither their structure nor function is well understood. The complexity of sea urchin maternal RNA is about $6 \%$ that of the genome, i.e. enough to code for about 30,000 proteins. This value is higher than that of messenger RNA populations of any other embryonic or adult tissue (1). Maternal RNA is not extensively translated in the oocyte (2), but the molecular mechanisms which "mask" maternal RNA from the translation machinary of the oocyte are not well understood, and have been the subject of a great

Abbreviations Used: EDTA, ethylenediaminetetraacetic acid; HAP, hydroxylapatite (BioRad); ODNA, DNA complimentary to RNA stored in the mature sea urch in oocyte; SDS, sodium dodecyl sulphate; TEACl, tetraethyl ammonium chloride. 
deal of research (eg. 3). The state of processing of sea urchin maternal RNA is not known. However, recent studies indicate that at least some of the RNA sequences are stored in the oocyte in a nonprocessed or incompletely processed form $(4,5)$. After fertilization, maternal RNA is "unmasked" and recruited onto polysomes where some or all of it directs translation during early embryogenesis.

The work reported here deals with the extent of evolutionary conservation of DNA which codes for maternal RNA (termed oocyte DNA or "ODNA") in sea urchins. The genus strongylocentrotus is particularly advantageous for such a study because, through the fossil record, a reasonable estimate exists regarding the time of divergence of the evolutionary lines leading to at least two species, i.e. $\underline{S}$. purpuratus and $\underline{S}$. franciscanus. The estimated time of their divergence is about $10 \mathrm{million}$ years ago (6). Also, extensive measurements have been made of the degree of sequence divergence of the total single-copy DNA of these congeners. Using methods similar to those reported here, the sequence divergence of these genomes has been estimated to be $10-19 \%$ depending on conditions of measurement and numerical handling of the data $(7,8,11)$. Thus, the data reported here allow comparison of the extent of evolutionary divergence of DNA which codes for maternal RNA, with divergence of single-copy DNA as a whole.

\section{Methods}

Preparation of driver DNAs

Unlabelled DNA for hybridization was prepared from frozen sperm of several individual sea urchins by SDS lysis and phenol extraction as described elsewhere (7). Driver DNA of average fragment length 800 nucleotides was prepared by shearing in a Virtis 60K homogenizer. The size of the resultant fragments was measured in isokinetic alkaline sucrose gradients which were centrifuged at 41,000 RPM for $24 \mathrm{H}$ in a Beckman SW 41 rotor and compared to internal size markers.

\section{Preparation of oocyte RNA}

RNA of mature oocytes of $\underline{S}$. purpuratus was prepared by 1 ys is in $7 M$ urea by Dounce homogenization, then deproteinization in $1: 1$ of phenol:m-cresol:8hydroxyquinoline plus chloroform:isoamyl alcohol (24:1). The deproteinized RNA was precipitated, then treated with DNase $(100 \mu \mathrm{g} / \mathrm{ml})$, then proteinase $\mathrm{K}$. The RNA was phenol extracted again, precipitated, resuspended, passed over a Sephadex G-100 column, then precipitated and stored at $-20^{\circ} \mathrm{C}$. This isolation is described in greater detail elsewhere (9). 


\section{Preparation of $\mathrm{H}^{3}-1$ abelled single-copy DNA}

Unlabelled S. purpuratus single-copy ONA was prepared by sequential selfhybridization and passage over hydroxylapatite as described elsewhere (8). It was labelled in vitro with tritium by "gap-translation", then bound to hydroxylapatite to remove unincorporated nucleotides. Self-hybridizing duplexes which can be artifactualiy generated by "gap-translation" were removed by disassociation, brief reassociation and hydroxylapatite binding. The specific-activity of the tracer was about $5 \times 10^{6} \mathrm{cpm} / \mu \mathrm{g}$ and the fragment length was about 300 nucleotides.

\section{Preparation of $\mathrm{H}^{3}-1$ abelled ODNA}

The $H^{3}$-labelled, single-copy DNA described above was enriched for those sequences present in mature oocyte RNA as described in detail elsewhere (9). Briefly, the labelled DNA was reassociated twice with a 700 fold excess of oocyte RNA; after each reassociation, un reacted RNA was digested with RNase, the DNA-RNA duplexes were phenol extracted, then bound to hydroxylapatite in $0.12 \mathrm{M}$ phosphate buffer. RNA was removed from the final duplex by treatment with $\mathrm{KOH}$.

\section{Assay of interspecies divergence of ODNA by hydroxylapatite chromatography}

An excess of sheared, unlabelled, driver DNA of $\underline{S}$. purpuratus or $\underline{S}$. franciscanus was heated to $95^{\circ} \mathrm{C}$ with $\mathrm{H}^{3}$-labelled ODNA, both of which were prepared as described above. Reassociation reactions were carried out in glass capillary tubes; each reaction contained $100 \mu \mathrm{g}$ of driver DNA and $3 \times 10^{3}$ counts of tracer in a volume of $50 \mu l$ of $0.41 \mathrm{M} \mathrm{Na}{ }^{+}$phosphate buffer ( $\mathrm{pH} 7.4), 10^{-3} \mathrm{M}$ EDTA and $0.05 \%$ SDS at $50^{\circ} \mathrm{C}$. Each hybridization was continued until completion of reassociation, then adjusted to $0.12 \mathrm{M}$ phosphate buffer and bound to $0.4 \mathrm{~g}$ columns of hydroxylapatite. Stability of the duplexes was determined by sequential increase in temperature and elution of fragments rendered single-strand at $4^{\circ} \mathrm{C}$ increments.

\section{Assay of interspecies divergence of ODNA by digestion with S1 nuclease}

The same amounts of driver and tracer DNAs as above were denatured, then reassociated to completion in $50 \mu 1$ of $1.5 \mathrm{M}$ tetraethyl ammonium chioride (TEACI). The reassociated duplexes were treated with $3 \mu 1$ single-strand specific S1 nuclease in $0.1 \mathrm{M} \mathrm{NaAC}, 0.05 \mathrm{M} \mathrm{HAC}, 10^{-3} \mathrm{M} \mathrm{ZnSO}_{4}\left(\mathrm{pH}_{4.3)}\right.$ for 1 hour at $37^{\circ} \mathrm{C}$ such that $90 \%$ of single strands were digested. An aliquot of the digestion products was saved for sizing (see below) and the rest was adjusted to 2.4M TEACl by passage over Sephadex G-100. The DNA was distributed into 16 Epindorf tubes which were placed in holes of an aluminum block which was heated at one end and cooled at the other to produce a temperature gradient (8). The aliquots were heated for 30 minutes; then digested with 51 nuclease as above, except with ten times more nuclease such that $99 \%$ of single-strands were digested. The extent of digestion in each aliquot was calculated from the fraction of counts excluded from Sephadex G-100 columns. The data of Figure 2 have been normalized to $100 \%$ digestion with $S 1$ at the highest temperature; actual digestions were $90.2 \%$ for $\underline{S}$. purpuratus and $91.0 \%$ for $\underline{S}$. franciscanus.

Measurement of duplex length by electrophoresis through alkaline agarose gels.

Measurement of stability of duplexes was corrected for the effect of duplex length. This was determined using an aliquot of the hybridization mixture described above, taken after the first treatment with 51 nuclease. This material was electrophoresed through a $3.5 \%$ agarose gel in $0.03 \mathrm{M} \mathrm{NaOH}, 2 \times 10^{-3} \mathrm{M}$ EDTA (8). In parallel lanes were run size standards generated by Hin F1 digestion of the plasmid pBR322 (eight fragments ranging in size from 1629 to 75 nucleotides). The gel was sliced into $1 \mathrm{~cm}$ pieces, then each piece was melted in $0.2 \mathrm{M} \mathrm{HCl}$, adjusted to neutrality, and counted in a liquid scintillation counter. 


\section{Results and Discussion}

The objective of the work reported here was to assess the extent of evolutionary divergence of DNA coding for maternal RNA relative to the previously determined divergence of total single-copy DNA in two species of sea urchin. To do this, a tracer made by sequential hybridization of $\underline{S}$. purpuratus $H^{3}-$ labelled single-copy DNA to excess $\underline{S}$. purpuratus maternal RNA, was hybridized to an excess of total DNA of $\underline{S}$. purpuratus and $\underline{S}$. franciscanus. The resultant duplexes were analyzed in two ways to determine their thermal stability. Since each degree reduction of $T_{M} 1 / 2$ (the half-melting point) corresponds to about $1 \%$ nucleotide sequence divergence (10), comparison of homologous (same species) and heterologous (different species) melting profiles can approximately quantitate the extent of evolutionary sequence change.

In the first experiment, $H^{3}-1$ abelled $\underline{S}$. purpuratus oDNA was reassociated with sheared, unlabelled, total DNA of $\underline{S}$. purpuratus and $\underline{S}$. franciscanus. The resultant duplexes were bound to hydroxylapatite, then eluted by washing the column at sequentially elevated temperatures. Figure 1 shows the thermal elution profiles obtained using driver DNA of the two species of sea urchin.

In the second experiment, the same DNAs were reassociated in the chaotropic solvent TEACl. TEACl has several effects on DNA reassociation, including increasing the rate of hybridization and decreasing the meiting temperature (8). Most importantly in context of these measurements, TEACl reduces the effect of base composition on thermal melting (11), thus yielding a sharper and more accurate melting profile. Other parameters, such as the relationship between $T_{M}$ reduction and sequence divergence, and the relationship between $T_{M}$ and fragment length, are not affected by TEACl. After reassociation, the duplexes were digested lightly with $S 1$ nuclease to render them more soluble. The DNA was divided into sixteen aliquots and heated individually to increasing temperatures, then assayed to determine the fraction in duplex by nearly complete S1 digestion and passage over Sephadex G-100 (see Methods section and reference 8). The resultant melting profiles are shown in figure 2. 

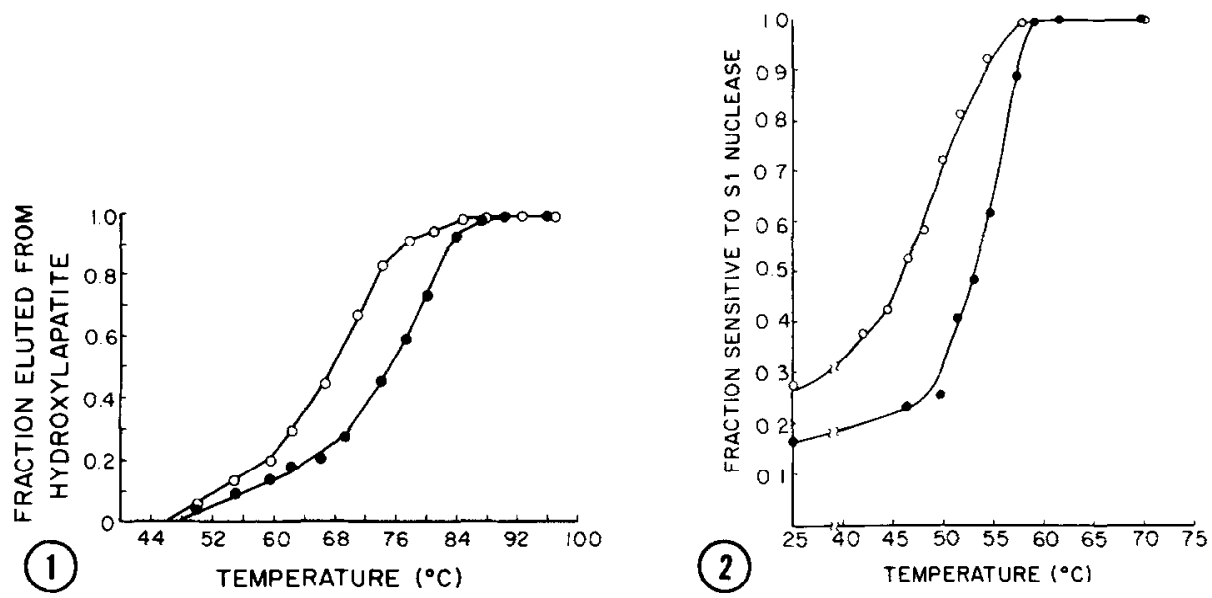

Figure 1: Thermal elution profile of $S$. purpuratus ODNA hybridized with $S$. purpuratus $(0)$ and $S$. franciscanus $(0)$ tota $\bar{T}$ DNA. $H^{3}$-label led S. purpuratus DNA complimentary to maternal RNA was prepared and hybridized with total, unlabeled DNA of the two sea urchin species as described in the Methods section. The resultant duplexes were bound to $0.4 \mathrm{~g}$ columns of hydroxylapatite in water-jacketed glass columns at $50^{\circ} \mathrm{C}$ in $0.12 \mathrm{M}$ phosphate buffer and $0.05 \%$ SDS. The hybrids were eluted by washing the columns with $0.12 \mathrm{M}$ phosphate buffer as the temperature was increased in $4^{\circ} \mathrm{C}$ increments.

Figure 2: Profiles of resistance to $S_{1}$ nuclease of duplexes formed between $S$. purpuratus ODNA and total DNA of $S$. purpuratus (0) and $S$. franciscanus (0). $\mathrm{H}^{3}$ labelled $S$. purpuratus DNA complimentary to maternaT RNA was prepared and hybridized with total, unlabelled DNA of the two sea urchin species in $1.5 \mathrm{M}$ IEACl as described in the Methods section. The resultant duplexes were adjusted to 2.4M TEACl and aliquoted into 16 tubes which were heated to increasing temperatures. The fraction of DNA in duplex at each temperature was manitored by resistence to Sl nuclease as described in the Methods section. Tm $1 / 2$ values (Table 1) were calculated not as the $50 \%$ point on the graph, but rather as the temperature at which half the counts which were resistent to $\mathrm{S} 1$ at $25^{\circ} \mathrm{C}$ were rendered sensitive to $\mathrm{Sl}$.

It is necessary to correct $T_{M} 1 / 2$ values generated by thermal melting to account for the effect of duplex length (10). This was measured by electrophoresis of S1 trimmed duplexes through alkaline agarose and monitoring of their mobility relative to standards (see Methods and reference 8 ). The average lengths of $S 1$ resistant duplexes measured by this method were 281 nucleotides for $\underline{S}$. purpuratus and 200 nucleotides for $\underline{S}$. franciscanus; it is to be expected that sequence divergence in the heterologous duplexes would result in a sight reduction in duplex length relative to the homologous case. The data of Figures 1 and 2, corrected for the effect of duplex length, are listed in Table 1. As shown in Table 1, since the evolutionary separation of the lines leading to $\underline{S}$. purpuratus and $\underline{S}$. franciscanus, ODNA has diverged $4.8-7.4^{\circ} \mathrm{C}$ (i.e. 4.8-7.4\%), depending on the method of measurement. Any value in this range is 
Table 1. Thermal stability of $S$. purpuratus ODNA reassociated with total DNA of $\underline{S}$. purpuratus and $\underline{S}$. franciscanus

A. Hydroxylapatite Method

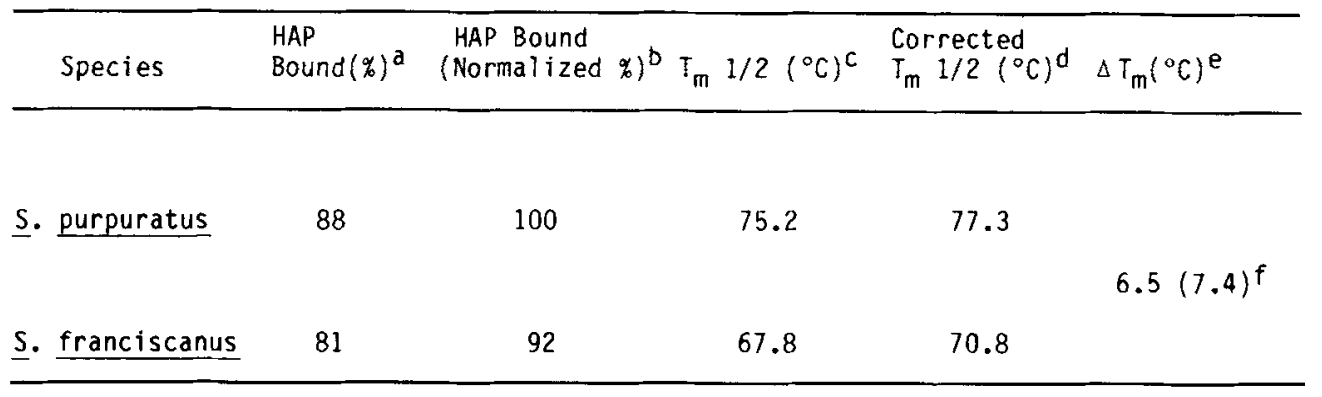

afraction of input counts which bound to hydroxylapatite at $45^{\circ} \mathrm{C}$.

braction of input counts which bound to hydroxylapatite at $45^{\circ} \mathrm{C}$ normalized

to $100 \%$ of homologous reaction.

CTemperature at which $50 \%$ of bound counts eluted from hydroxylapatite

(see Figure 1).

$\mathrm{d}_{\mathrm{T}} 1 / 2$ corrected upward to normalize for the reduction due to fragment

length (reduction $\left({ }^{\circ} \mathrm{C}\right)=600 /$ length). Fragment lengths were $\mathrm{S}$. purpuratus, 281 NT; S. franciscanus, 200 NT.

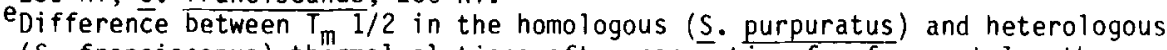

(S. franciscanus) thermal elutions after correction for fragment length.

f value generated in a duplicate run (data not shown).

\section{B. TEACl Method}

\begin{tabular}{llll} 
Species & Sl & Resistant $(\%)^{\mathrm{a}} \begin{array}{l}\text { Sl Resistant } \\
(\text { Normalized } \%)^{b} \mathrm{~T}_{\mathrm{m}} 1 / 2\left({ }^{\circ} \mathrm{C}\right)^{\mathrm{C}}\end{array} \mathrm{T}_{\mathrm{m}} 1 / 2\left({ }^{\circ} \mathrm{C}\right)^{\mathrm{d}} \Delta \mathrm{T}_{\mathrm{m}} 1 / 2\left({ }^{\circ} \mathrm{C}\right)^{\mathrm{e}}$ \\
\hline
\end{tabular}

$\begin{array}{lllll}\text { S. purpuratus } & 48 & 100 & 54.3 & 56.4\end{array}$

S. franciscanus $\quad 44 \quad 92 \quad 48.6 \quad 51.6$

\footnotetext{
afraction of input counts which were $S 1$ resistant at room temperature prior to the second ( $i . e$. more stringent) Sl digestion step (see Methods).

bAs above, but normalized to $100 \%$ resistance in the homologous reassociation.

CThe temperature at which half the DNA resistant to $S 1$ at room temperature was rendered S1 sensitive.

${ }^{d}$ Corrected for the effect of fragment length on $T_{m} 1 / 2$.

${ }^{e}$ Difference between $T_{m} 1 / 2$ of homologous and heterologous duplexes.
}

significantly below the divergence of total single-copy DNA in these species which has been reported to be $10-19^{\circ} \mathrm{C}$, depending on the method of measurement and data analysis $(7,8,11)$.

There are at least three possible interpretations of this result. The first is that there are selective pressures which constrain the evolutionary 
sequence divergence of all or most of the DNA which codes for maternal RNA. A second interpretation is that some DNA coding for maternal RNA molecules is under heavy selection pressure which allows very little sequence divergence, but DNA complimentary to other maternal RNA molecules is free to diverge about as rapidly as total single-copy DNA. The measurements reported in Table 1 would then represent an average of these two classes of maternal RNA-coding DNA. Finally, each maternal RNA molecule might be composed of regions of high and low divergence, the average of which is reflected in the measurements reported here.

It appears that much or all maternal RNA is stored in the oocyte in an unprocessed, or incompletely processed, form (5). This incomplete state of processing may contribute to the "masking" of maternal RNA from translation prior to fertilization. If, as is likely, the structure of maternal RNA is similar to the structure of nuclear RNA, part of each molecule would consist of protein-coding sequence and part would consist of introns, leader/trailer sequences and possibly flanking sequences as well. In some systems, protein coding DNA is known to diverge more slowly during evolution than total single-copy DNA (e.g. 12). Thus, it seems quite possible that each maternal RNA molecule consists of conserved, protein-coding regions and less conserved non-coding sequences, and that the measurements reported here reflect this configuration.

\section{Acknowl ed gements}

This work was carried out while I was a postdoctoral fellow in the laboratories of Drs. Eric Davidson and Roy Britten at the California Institute of Technology. I gratefully acknowledge their advice and assistance.

\section{References}

1. Galau, G. A., Klein, W. H., Davis, M. M., Wold, B. J., Britten, R. J. and Davidson, E. H. (1976) Cell 7, 487-499.

2. Davidson, E. H. (1976) In: Gene Activity in Early Development. Academic Press, New York. pp 139-236.

3. Jenkins, N. A., Kaumeyer, J. F., Young, E. M. and Raff, R. A. (1978) Dev. Biol. 63, 279-289.

4. Thomas, T. L., Britten, R. J. and Davidson, E. H. (1982) Dev. Biol. 94, 230-239.

5. Davidson, E. H., Hough-Evans, B. R. and Britten, R. J. (1982) Science 217 , 17-26.

6. Smith, A.B. (1981) Paleontology 24, 779-798. 
7. Angerer, R. C., Davidson, E. H. and Britten, R. J. (1976) Chromosoma 56, 213-226.

8. Hall, T. J., Grula, J. W., Davidson, E. H. and Britten, R. J. (1980) J. Mol. Evol. 16, 95-1.10.

9. Hough-Evans, B. R., Wold, B. J., Ernst, S. G., Britten, R. J. and Davidson, E. H. (1978) Dev. Bio1. 60, 258-277.

10. Britten, R. J., Graham, D. E. and Neufeld, B. R. (1974) In: Methods in Enzymology, 29E, Grossman and Moldave, eds. (New York: Academic Press) pp. 363-406.

11. Grula, J. W., Hal1, T. J., Hunt, J. A., Giugni, T. D., Graham, G. J., Davidson, E. H. and Britten, R. J. (1982) Evolution 36, 655-676

12. Rosbash, M., Campo, M. S. and Gummerson, K. S. (1975) Nature 258, 682-684. 